TITLE:

\title{
Promoting Open Access by the Kyoto University Library
}

$\operatorname{AUTHOR}(\mathrm{S})$ :

Nishioka, Chifumi

\section{CITATION:}

Nishioka, Chifumi. Promoting Open Access by the Kyoto University Library. Proceedings of the International Congress on Advanced Applied Informatics 2018: 462-465

\section{ISSUE DATE:}

2018

URL:

http://hdl.handle.net/2433/243231

\section{RIGHT:}

(C) 2018 IEEE. Personal use of this material is permitted. Permission from IEEE must be obtained for all other uses, in any current or future media, including reprinting/republishing this material for advertising or promotional purposes,

creating new collective works, for resale or redistribution to servers or lists, or reuse of any copyrighted component of this work in other works.; This is not the published version. Please cite only the published version.; この論文は出版社版

でありません。引用の際には出版社版をご確認ご利用ください。 


\title{
Promoting Open Access by the Kyoto University Library
}

\author{
Chifumi Nishioka \\ Kyoto University Library \\ Kyoto, Japan \\ Email: nishioka.chifumi.2c@kyoto-u.ac.jp
}

\begin{abstract}
Over the decades, the Open Access movement has evolved with the support by academic communities. Following this movement, Kyoto University adopted the Kyoto University Open Access policy in 2015 and has launched the Open Access promotion project in 2016. The project aims to promote open access to scholarly articles as well as open access to rare materials (e.g., manuscripts). In this paper, we summarize our systems to advance open access, focusing on our institutional repository for scholarly articles as well as our digital archive system for rare materials.
\end{abstract}

Keywords-open access; open science; institutional repository; digital archive;

\section{INTRODUCTION}

Open access to scholarly articles refers to the removal of barriers including price barriers and permission barriers (i.e., copyright and licensing restrictions) from accessing them [1]. Over the decades, the Open Access movement has evolved with the support by academic communities. Following this movement, Kyoto University adopted the Kyoto University Open Access policy ${ }^{1}$ in 2015. The policy mandates faculty members of Kyoto University to make their journal articles public on the web using our institutional repository KURENAI (Kyoto University Research Information Repository $)^{2}$. Furthermore, we have launched the Open Access promotion project ${ }^{3}$ in 2016. The project aims to enhance our capabilities of supporting research by taking the following actions: (1) promote open access to research outcomes (e.g., journal articles) through KURENAI; (2) digitize our rare materials, which include national treasure, important cultural properties, and other historically important manuscripts, maps, and drawings, and make them open access in the digital archive system, in order to improve availabilities of resources for research in humanities and social sciences; (3) distribute the above-mentioned scholarly contents internationally; (4) develop human resources for the management of research data including open access in accordance with open science and research integrity; and (5) organize a project team led by experts and train research support staffs systematically.

In this paper, we describe characteristics of our systems to advance open access, focusing on (1) and (2). Specifically,

\footnotetext{
${ }^{1}$ http://www.kulib.kyoto-u.ac.jp/uploads/oapolicy.pdf

${ }^{2}$ https://repository.kulib.kyoto-u.ac.jp/dspace/?locale=en

${ }^{3}$ http://www.kulib.kyoto-u.ac.jp/content0/1373844?lang=en
}

we elaborate on our institutional repository, which supports open access to scholarly articles, and our digital archive system, which promotes open access to rare materials. Our institutional repository KURENAI was launched in 2006. Since then, KURENAI has disseminated intellectual outcomes by Kyoto University members, including department bulletins, dissertations, and journal articles. In terms of the digital archive system, we have digitized rare materials for over 20 years and delivered them on different websites. To disseminate the digital images more efficiently, we officially launched the Kyoto University Rare Materials Digital Archive $^{4}$, a novel digital archive system on December 1, 2017. It supports the IIIF (International Image Interoperable Framework) ${ }^{5}$, which enables interoperable use of images over different institutions by defining a couple of common APIs. Thus, the images available on the digital archive system can be accessed and reused using the APIs.

The reminder of this paper is organized as follows: Section II elaborates on our institutional repository. Thereafter, Section III provides the details of our digital archive system before concluding this paper in Section IV.

\section{INSTITUTIONAL REPOSITORY}

This section introduces our institutional repository KURENAI. It was launched in 2006 to disseminate intellectual outcomes produced by Kyoto University members. The institutional repository has been developed based on DSpace [2]. Basing DSpace, we added an additional function described in Section II-A, which facilitates faculty members to register contents. As of February 28, 2018, KURENAI stores 187,829 contents including department bulletins, dissertations, and journal articles. 171,847 of them include full-texts of the contents.

\section{A. Deposit System}

This section introduces the deposit system as one of characteristic functions of KURENAI. In 2016, we added the deposit system to KURENAI, in order to facilitate faculty members (or substitutes registered by them) to register contents, as the Open Access policy mandates them to make their journal articles public using KURENAI. Figure 1 shows a screenshot of the deposit system. The rectangular A in

\footnotetext{
${ }^{4}$ https://rmda.kulib.kyoto-u.ac.jp/

${ }^{5}$ http://iiif.io/
} 


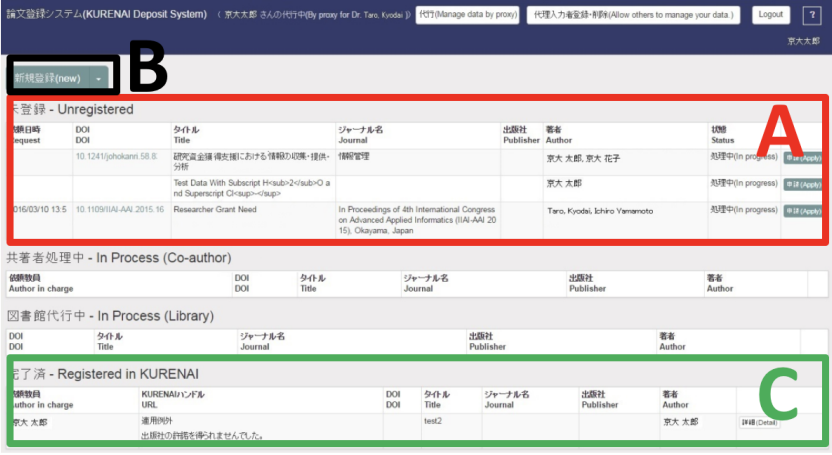

Figure 1. The deposit system of KURENAI.

Figure 1 notifies unregistered journal articles authored by a user. The deposit system fetches the information of the unregistered journal articles from external databases such as Scopus $^{6}$ and researchmap ${ }^{7}$. A user clicks one of the unregistered journal articles, and then he can upload the final published version or the author's final manuscript of the corresponding journal article. In addition, a user can register and publish journal articles that are not captured by databases as well as contents other than journal articles from the rectangular B in Figure 1. In this case, a user registers metadata of the content and uploads the corresponding file. After submission of a content by a user, librarians manually check the license of the submitted content, in order to ensure that KURENAI does not make any copyright infringement. The rectangular $\mathrm{C}$ in Figure 1 shows a list of contents that have been made public on KURENAI.

Please note that if the license of a journal article is CC$\mathrm{BY}^{8}$, librarians download the journal article and make it public on KURENAI without asking to authors.

Figure 2 shows the number of contents submitted through the deposit system over the past two years. We observe that the number of contents has increased gradually despite a huge spike in February, 2017. The most likely reason of the spike is that we made presentations about the open access policy and the deposit system several times at faculty meetings in January and February, 2017. Faculty members who listened to the presentations probably accessed the deposit system and registered their contents.

\section{B. Other Activities}

This section describes other activities for KURENAI.

Links from and to the Activity DB: KURENAI is linked to the Activity Database on Education and Research (Activity DB $)^{9}$, which provides the information of educational and research activities of faculty members in Kyoto University.

\footnotetext{
${ }^{6} \mathrm{https}: / /$ www.scopus.com/freelookup/form/author.uri

${ }^{7}$ https://researchmap.jp/public/about/

${ }^{8}$ https://creativecommons.org/

${ }^{9}$ https://kyouindb.iimc.kyoto-u.ac.jp/view/index_e.html
}

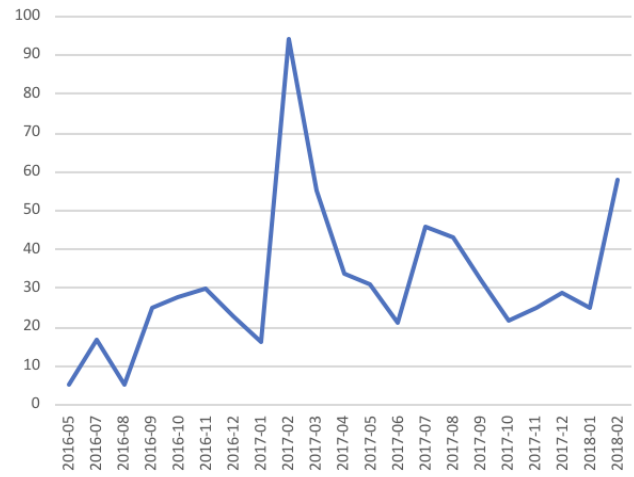

Figure 2. The number of submitted contents using the deposit system over past two years.

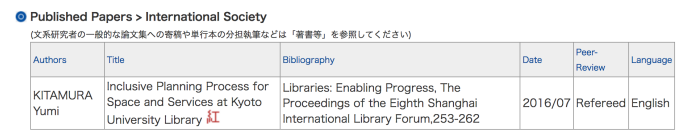

Figure 3. An example of the link to KURENAI from the Activity DB. The red icon in the figure provides a link to the corresponding content on KURENAI.

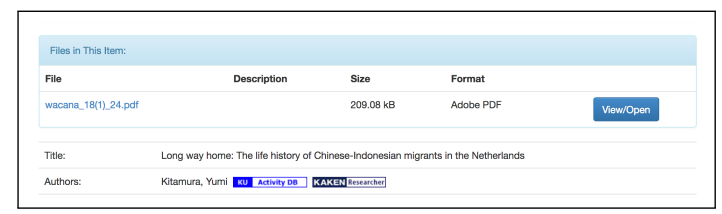

Figure 4. An example of the link to the Activity DB from KURENAI. The blue icon in the figure provides a link to the corresponding researcher's information page on the Activity DB.

When a faculty member registers a content onto KURENAI using the deposit system, the deposit system provides an option to automatically register the content to the Activity DB as well. When a faculty member registers a content onto the Activity DB, the Activity DB asks him to upload the corresponding file to KURENAI. In these cases, the record of a scholarly article on the Activity DB provides a link to the corresponding page on KURENAI, as shown in Figure 3. In addition, KURENAI provides a link to the Activity DB. In Figure 4, the blue icon next to the author name gives a link to the corresponding researcher's information page on the Activity DB.

Persistent identifier: To ensure permanent access, we add persistent identifiers (i.e., DOIs) to doctoral dissertations. In addition, we provide persistent identifiers to other contents such as department bulletins, if an author requests. DOIs are provided by Japan Link Center $(\mathrm{JaLC})^{10}$. If an author requests, DOIs can be given by CrossRef ${ }^{11}$. As of

\footnotetext{
${ }^{10} \mathrm{https} / / /$ japanlinkcenter.org/top/english.html

${ }^{11}$ https://www.crossref.org/
} 
February 28, 2018, KURENAI includes 23,996 contents with DOIs. DOIs of 22,604 contents are given by JaLC and those of 1,392 contents are provided by CrossRef.

Internationalization: We have added English metadata to contents in KURENAI, to improve their discoverability and make them more visible from outside Japan. Specifically, we transcribe Japanese author names into Roman characters. In addition, we add English titles to metadata, if the full-text of a content includes an English title.

ORCID: In the future, we investigate how we exploit ORCIDs for KURENAI, since Kyoto University became an ORCID member organization in the end of 2017.

\section{Digital ARChive System}

This section describes the details of our digital archive system, the Kyoto University Rare Materials Digital Archive, which was launched on December 1, 2017. Regarding characteristics of the digital archive system, it supports the IIIF, which enables interoperable use of images over institutions by defining common APIs. As of February 27, 2018, the digital archive stores 566,598 images of 5,980 titles.

\section{A. IIIF (International Image Interoperable Framework)}

Over the decades, a lot of institutions have digitized rare materials and made them public on the web. The infrastructures to store images and the web applications to deliver them has remained institution-specific. Thus, researchers who study images held by different institutions must switch from website to website, and must learn different interfaces and tools specific to each site. The IIIF (International Image Interoperable Framework) [3] was launched to address these challenges. Kyoto University Library Network has been an IIIF consortium member since December, 2016. So far, the IIIF has defined four APIs, which are the Image API, the Presentation API, the Search API, and the Authentication API. Among them, our digital archive system uses the Image API and the Presentation API. The Image API defines a web service that returns an image in response to a standard HTTP or HTTPS request. The URI specifies the region, size, rotation, quality characteristics, and format of the requested image. For instance, when using an image as a thumbnail, a small value is set as the size of the image in the URI. The Presentation API specifies a web service that returns JSON-LD structured documents (i .e., IIIF manifests). IIIF manifests describe the structure and layout of a digitized object or other collection of images. In other words, the Presentation API focuses on the metadata for driving a viewing experience including image sequence, display labels, and licensing.

\section{B. System Configuration}

Figure 5 illustrates the system configuration of the digital archive system. The system comprises two main components: a content management system (CMS) and image

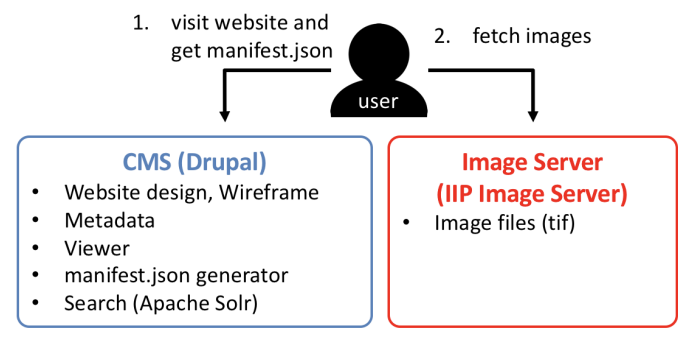

Figure 5. System configuration of the digital archive system.

server. We use Drupal and IIP Image server as CMS and image server, respectively. The CMS manages and keeps contents other than images, including website designs, metadata and introductions of the rare materials, and viewers. The image server stores images of the rare materials. The images are delivered to a viewer on the CMS using the IIIF Image API. IIIF manifests are automatically generated by a Drupal module based on metadata stored in the CMS.

\section{Functions}

This section introduces functions of the digital archive system. Figure 6 is a screenshot of the top page of the digital archive system. "Pick Up" in the middle of Figure 6 provides several categories, in which important or/and popular rare materials are classified. Collections are given in "Collection" of Figure 6 in the bottom. As of March 30, 2018, the digital archive system provides eight pick ups and 22 collections. A user can switch languages with the toggle displayed in the upper right. Figure 7 shows a screenshot of a bibliography page. It provides the bibliographical information including record identifier, title, publication year, and note. Universal Viewer, which is one of the most popular IIIF-compatible image viewers, is embedded in the top of the page. Thus, a user can look through images on the page. In the bottom of the image viewer, there are three icons, which are IIIF manifest, Universal Viewer, and Mirador. IIIF manifest provides a link to the IIIF manifest file of the corresponding bibliography. By clicking Universal Viewer and Mirador, a user can open the images on each viewer. We support these two viewers, since they are the most popular viewers in the IIIF community.

\section{Other Activities}

In this section, we describe other noteworthy activities related to the digital archive system.

Links from OPAC: A user can reach to the images of rare materials not only from the digital archive system but also from KULINE ${ }^{12}$, which is the OPAC (Online Public Access Catalog) of Kyoto University. As shown by the red rectangular in Figure 8, the bibliography page on KULINE provides a link to the corresponding bibliography page on

\footnotetext{
${ }^{12}$ https://kuline.kulib.kyoto-u.ac.jp/?lang=english
} 


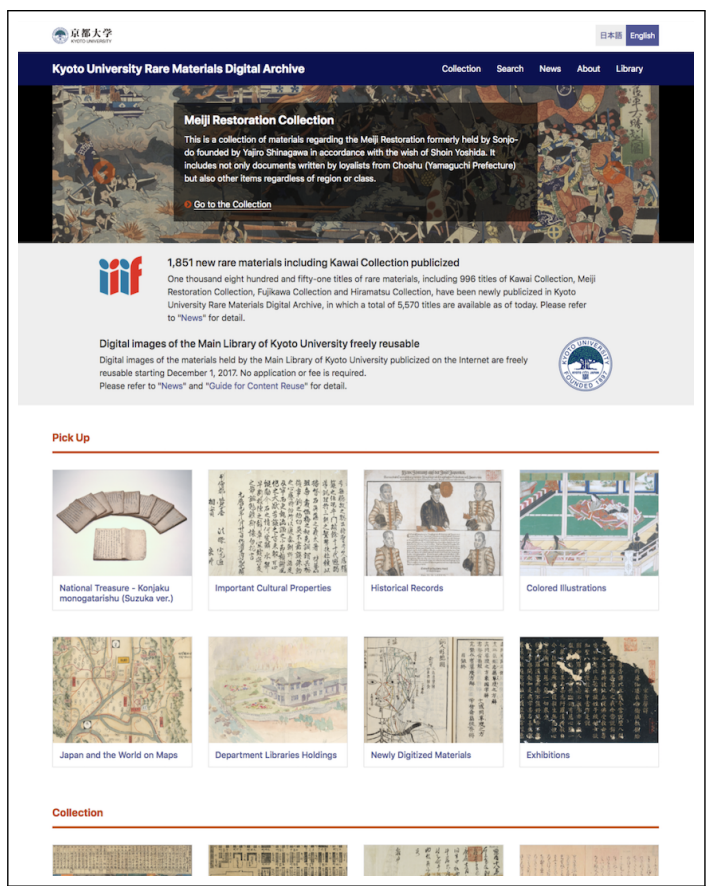

Figure 6. Top page of the Kyoto University Rare Materials Digital Archive.

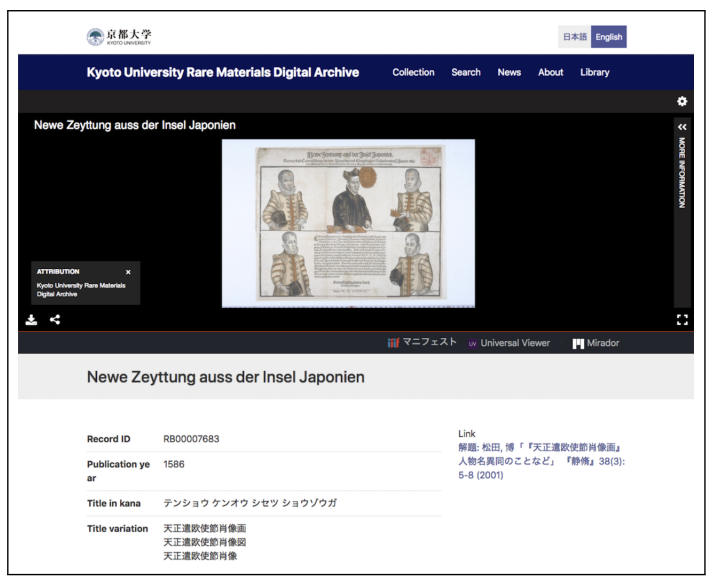

Figure 7. Bibliography page.

the digital archive system. KULINE and the digital archive system store the identical metadata of the rare materials. KULINE enables users to find rare materials using advanced search, which is not given by the digital archive system.

Conditions of the use: To encourage academic communities to use images in the digital archive system, we revised the conditions of the use ${ }^{13}$ on December 1, 2017. Unless specifically stated, the images owned by the Main Library and the Yoshida-South Library of Kyoto University are available for users to copy, adapt, or redistribute in any medium without application or fee under the following

\footnotetext{
${ }^{13}$ https://rmda.kulib.kyoto-u.ac.jp/en/reuse
}

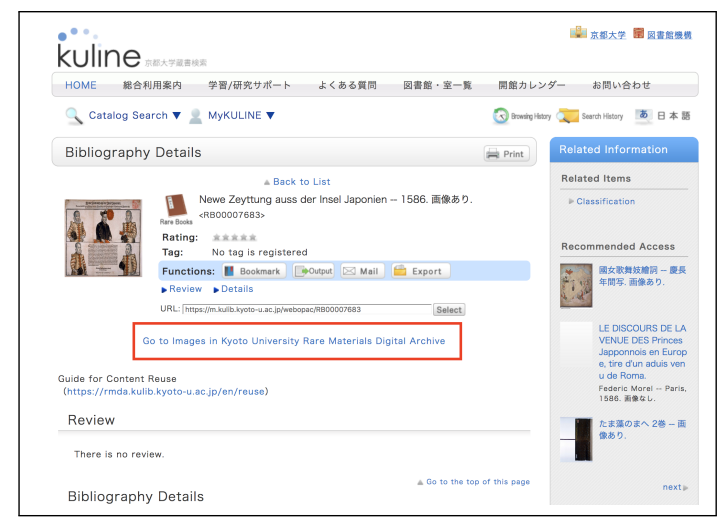

Figure 8. A Link to the digital archive system from KULINE (OPAC)

conditions: (i) indicate which libraries hold the original materials of the images; (ii) provide a link to the image, when using it on a website; and (iii) indicate if changes were made to the images. We hope the revision of the conditions of the use will promote studies in the rare materials.

Internationalization: We add English metadata to the rare materials to improve their discoverability.

\section{CONCLUSION}

This paper introduced our systems to promote Open Access by Kyoto University Library, focusing on our institutional repository and digital archive system. Our institutional repository provides the deposit system that facilitates submission of journal articles. In addition it connects with other databases such as the Activity DB. In the future, we investigate how we exploit ORCIDs. Our digital archive system supports the IIIF, which enables interoperable use of images over different institutions. To encourage the use of images, we revised the conditions of the use. We hope these systems facilitate the distribution of scholarly contents and contribute to academic communities.

\section{ACKNOWLEDGMENT}

We would like to thank our colleagues, especially Yuka Fujiwara and Fuko Hojo, for providing the information regarding KURENAI and the digital archive system.

\section{REFERENCES}

[1] P. Suber, "Open access overview," https://legacy.earlham.edu/ $\sim$ peters/fos/overview.htm, 2004, [Online; accessed 10-April2018].

[2] M. Smith, M. Barton, M. Bass, M. Branschofsky, G. McClellan, D. Stuve, R. Tansley, and J. H. Walker, "DSpace: An open source dynamic digital repository," 2003.

[3] S. Snydman, R. Sanderson, and T. Cramer, "The international image interoperability framework (iiif): A community \& technology approach for web-based images," in Archiving Conference. Society for Imaging Science and Technology, 2015, pp. 16-21. 